\title{
Using Strength of Fertility Motivations to Identify Family Planning Program Strategies
}

CONTEXT: Use of unmet need for family planning to identify prospective clients may misrepresent the actual family planning needs of a population, given that a large proportion of women have ambivalent fertility desires.

METHODS: Survey data for 1998 and 2003 from Burkina Faso, Ghana and Kenya were used to examine the fertility desires and motivations of women who said they wanted to delay or limit childbearing. A question on how much of a problem it would be if women found out they were pregnant in the next few weeks measured the strength of their fertility motivations.

RESULTS: In Burkina Faso and Ghana, about a quarter of women who said they wanted to delay or limit childbearing also reported that it would be no problem or a small problem if they became pregnant soon. This response pattern was equally common among contraceptive users and nonusers. In Kenya, more than four in 10 women gave such ambivalent responses. Among women with an unmet need for means of delaying or limiting childbearing, 16-31\% of those in Burkina Faso and Ghana, and 30-56\% of those in Kenya, said that getting pregnant in the next few weeks would be no problem or a small problem.

CONCLUSIONS: It is critical to consider the strength of fertility motivations when determining which women have family planning needs. Targeting women who are the most motivated to avoid childbearing will likely have the greatest impact on reducing unintended pregnancy in Sub-Saharan Africa.

International Family Planning Perspectives, 2006, 32(4):185-191
By llene S. Speizer

Ilene S. Speizer is research associate professor, Department of Maternal and Child Health, University of North Carolina School of Public Health, and research associate, MEASURE Evaluation Project, both in Chapel Hill, NC, USA.
In developing countries, policymakers and program planners often use unmet need as a measure of the unfulfilled demand for family planning methods and services. Unmet need represents the family planning needs of fecund women who are sexually active, do not use contraceptives and want to delay or limit childbearing. One study based on data from 20 developing countries demonstrated that the level of unmet need varies depending on which stage of the fertility transition a country is undergoing. ${ }^{l}$ Countries with a high total fertility rate (TFR) and a high demand for children typically have a low level of unmet need, as do countries with a low TFR and generally high contraceptive use. Unmet need is highest in countries that are in the middle stages of their fertility transition-when desired family size is changing rapidly and the demand for family planning services is substantial.

Yet the use of unmet need to identify program strategies has been questioned, because in countries where contraceptive use is rising, many unintended pregnancies are the consequence of contraceptive failure or discontinuation. ${ }^{2}$ One study estimated that the TFR in most countries could be reduced by a fifth to nearly a half if births attributed to contraceptive failure or discontinuation for any reason other than a desire to become pregnant were eliminated. ${ }^{3}$ Furthermore, this study found that more than half of unwanted pregnancies were the result of contraceptive failure or discontinuation. Supporting effective contraceptive use among current users, rather than emphasizing contraceptive adoption among new users, especially in countries where fertility is on the decline, is considered an important programmatic strategy. ${ }^{4}$

In contrast, a study in Upper Egypt found that women who do not use contraceptives but have an unmet need for family planning contribute the largest share of unintended (mistimed or unwanted) pregnancies. ${ }^{5}$ Because much of Sub-Saharan Africa has levels of contraceptive use and unmet need similar to those of Upper Egypt, this study recommended that family planning programs should continue to focus on the promotion of contraceptive use among women and men with unmet need.

Targeting women who have recently adopted family planning, and so are at an elevated risk of discontinuation or contraceptive failure, and identifying women with an unmet need are both important strategies for improving access to family planning services. However, using these strategies to identify women at greatest risk of discontinuation assumes that there is a strong, consistent association between reported fertility desires and contraceptive use.

A number of studies from the United States have demonstrated inconsistencies between women's reported fertility desires and their contraceptive use. ${ }^{6}$ In a U.S. study, about one-third of contraceptive failures (pregnancies that occur when a method is used) were reported to have occurred at about the right time and were therefore classified (accord- 


\begin{tabular}{|c|c|c|c|c|c|c|}
\hline Measure & $\begin{array}{l}\text { Burkina } \\
\text { Faso } \\
2003\end{array}$ & $\begin{array}{l}\text { Ghana } \\
2003\end{array}$ & $\begin{array}{l}\text { Kenya } \\
2003\end{array}$ & $\begin{array}{l}\text { Burkina } \\
\text { Faso } \\
\text { 1998-1999 }\end{array}$ & $\begin{array}{l}\text { Ghana } \\
\text { 1998-1999 }\end{array}$ & $\begin{array}{l}\text { Kenya } \\
1998\end{array}$ \\
\hline Total fertility rate & 5.9 & 4.4 & 4.9 & 6.4 & 4.4 & 4.7 \\
\hline \multicolumn{7}{|l|}{ Contraceptive use (\%) } \\
\hline Any method & 13.8 & 25.2 & 39.3 & 11.9 & 22.0 & 39.0 \\
\hline Modern method & 8.8 & 18.7 & 31.5 & 4.8 & 13.3 & 31.5 \\
\hline \multicolumn{7}{|l|}{ Unmet need (\%) } \\
\hline To delay & 21.8 & 21.7 & 14.4 & 19.0 & 8.7 & 14.0 \\
\hline Tolimit & 7.0 & 12.3 & 10.1 & 6.8 & 7.8 & 9.9 \\
\hline \multicolumn{7}{|l|}{ Fertility desire (\%)* } \\
\hline Want child soon (<2 yrs.) & 37.5 & 26.9 & 22.3 & 42.0 & 29.2 & 21.1 \\
\hline \multicolumn{7}{|l|}{ Want to delay } \\
\hline childbearing ( $\geq 2$ yrs.) & 29.1 & 31.9 & 25.2 & 21.4 & 25.1 & 22.2 \\
\hline Want child, undecided when & 3.4 & 2.8 & 1.9 & 7.0 & 3.3 & 1.4 \\
\hline Undecided & 3.0 & 3.3 & 2.0 & 6.3 & 5.3 & 4.1 \\
\hline Want no more children & 27.1 & 35.1 & 48.6 & 23.3 & 37.1 & 51.2 \\
\hline \multicolumn{7}{|c|}{$\begin{array}{l}\text { How much of a problem would it be if you found } \\
\text { out you were pregnant in the next few weeks? (\%)† }\end{array}$} \\
\hline No problem & 15.2 & 14.1 & 28.8 & na & na & na \\
\hline Small problem & 11.3 & 7.5 & 14.1 & na & na & na \\
\hline Big problem & 73.5 & 78.4 & 57.1 & na & na & na \\
\hline \multicolumn{7}{|c|}{$\begin{array}{l}\text { How happy would you be if you found out you were } \\
\text { pregnant in the next few weeks? (\%)‡ }\end{array}$} \\
\hline Happy & na & na & na & 11.6 & 4.2 & 17.1 \\
\hline Would not matter & na & na & na & 7.5 & 14.2 & 20.1 \\
\hline Unhappy & na & na & na & 80.9 & 81.6 & 62.9 \\
\hline
\end{tabular}

*Includes only women who were not pregnant, not amenorrheic (postpartum) and not sterilized, who did not declare themselves infecund, who had had intercourse in the last year, and who were currently married or living with a partner. Includes only women who wanted to delay childbearing for two or more years or to limit childbearing. ¥The Burkina Faso and Kenya results include only women who wanted to delay childbearing. The Ghana results include women who wanted to delay or limit childbearing. Note: na=not available.

ing to the standard definition) as intended. ${ }^{7}$ Moreover, a quarter of women who experienced a contraceptive failure and whose pregnancies were classified as unintended also said they were happy or very happy about the pregnancy. This has led to a debate on whether some women who experience contraceptive failure are ambivalent about avoiding pregnancy, and therefore use contraceptives inconsistently. Although such ambivalence was first identified among contraceptive users, many nonusers may also be ambivalent about getting pregnant, which may affect their motivation to use family planning.

A longitudinal study of unmet need in Morocco found that among women with an unmet need for means of limiting births, more than half had a birth in the three-year follow-up period. ${ }^{8}$ Two-thirds of these births were later reported as wanted. Whether this reflects ambivalence or rationalization is not clear, but both are possible explanations. Other research has indicated that many women are ambivalent toward contraception and thus are less likely to use a family planning method, ${ }^{9}$ leaving them at risk of a mistimed or unwanted pregnancy.

In Sub-Saharan Africa, recent efforts by international donors are attempting to reinvigorate family planning programs that have been underfunded. ${ }^{10}$ The question of whether to focus resources on increasing the number of new users or improving the effectiveness of use among current users is especially salient, because many countries are beginning the fertility transition and are expected to have high levels of unmet need and unintended pregnancy over the transitional period. At the end of the 1990s, roughly a quarter to a third of women in Sub-Saharan Africa had an unmet need for family planning. ${ }^{11}$ Moreover, in countries such as Kenya and Ghana, recent research has explored why fertility rates have stalled in the middle of the fertility transition, instead of following the expected pattern of continuously declining fertility. ${ }^{12}$ New policy and program strategies have been instituted in Kenya and Ghana to address their stalled fertility rates. ${ }^{13}$ Because many women may have ambivalent fertility intentions, these strategies also need to address the decision-making processes that are involved in fertility and family planning.

This article is one of the first to explore the strength of fertility motivations and the ambivalent fertility desires among women in Sub-Saharan Africa. This type of information is crucial for identifying which women are most at risk of having unintended pregnancies and for determining effective strategies to meet their family planning needs.

\section{DATA AND METHODS}

We used Demographic and Health Survey (DHS) data on pregnancy history, use of family planning and fertility preferences collected in 1998-1999 (hereafter referred to as 1998) and 2003 from women in three Sub-Saharan African countries: Burkina Faso, Ghana and Kenya. ${ }^{14}$

The 2003 data are of particular interest because a novel question was included in all three surveys. All respondents who wanted to delay childbearing for two or more years or to limit childbearing, or who were unsure about future childbearing, were asked: "How much of a problem would it be if you found out you were pregnant in the next few weeks?" Response options were "no problem," "small problem" and "big problem." Respondents' answers, in combination with their reported fertility desires, were used to assess their motivation to avoid pregnancy. Our analysis included only those women who wanted to delay or limit childbearing.

The 1998 surveys included a similar question: "How happy would you be if you found out you were pregnant in the next few weeks?" Response options were "happy," "doesn't matter" and "unhappy." In the 1998 Ghana survey, all women who wanted to delay or limit births were asked this question. In the 1998 Kenya and Burkina Faso surveys, only women who wanted a child soon or who wanted to delay childbearing were asked this question. For these two countries, we included only women who wanted to delay childbearing.

For analyses of fertility intentions, contraceptive use and motivation to avoid pregnancy, we included only women who were formally married or living with a partner, and who were currently exposed to the risk of getting pregnant. In particular, we excluded women who were pregnant, amenorrheic (postpartum) or sterilized; who declared themselves infecund; or who had not had intercourse in the last 
year. Women who reported that they had last had intercourse before the birth of their last child were also excluded.

To examine how fertility intentions relate to contraceptive use and motivations, we focused on women who reported that they wanted to delay childbearing for two or more years (delay) and women who wanted to stop childbearing (limit). Those who wanted more children but were unsure of the timing were excluded because they had not been asked whether getting pregnant would be a problem. In addition, the small number of women who reported that they were undecided on future childbearing were excluded because it was difficult to assess how motivated they were to avoid pregnancy. For the Kenya and Burkina Faso comparisons of fertility motivations between 1998 and 2003, we reduced the sample further to include only women who wanted to delay childbearing, since these are the women who were asked the "happiness" and "problem" questions.

All surveys used a multistage sampling strategy and were weighted to be nationally representative. Analyses adjusted for the sampling design and were performed using Stata 9.

\section{RESULTS}

The three countries selected for this analysis provide a rich perspective on the varying levels of fertility, contraceptive use and unmet need in Sub-Saharan Africa. The TFR was highest in Burkina Faso, at 5.9 births per woman aged 15-49 in 2003, a decline from 6.4 births five years earlier (Table 1, page 186). In Kenya, the TFR for 2003 was 4.9, up from 4.7 in the earlier survey. In Ghana, the rate remained constant over this period at 4.4 births per woman. Use of any method of contraception varied widely in 2003-from 39\% among women who were married or living with a partner in Kenya (unchanged from 1998), to 25\% in Ghana (22\% in 1998), to 14\% in Burkina Faso (12\% in 1998). The use of modern contraceptives followed a similar pattern: remaining steady at 32\% in Kenya, rising from 13\% to 19\% in Ghana, and rising from 5\% to 9\% in Burkina Faso.

Unmet need also varied across the three countries. Among Kenyan women in 2003, 14\% had an unmet need for means of delaying births and 10\% had an unmet need for means of limiting births; the values for 1998 are nearly identical. In Ghana in 2003, 22\% of women had an unmet need for means of delaying births and $12 \%$ had an unmet need for means of limiting births. These values had increased since 1998, as women began to want smaller families. Finally, in Burkina Faso in 2003, 22\% of women had an unmet need for means of delaying but only $7 \%$ had an unmet need for means of limiting childbearing; these rates had changed little since the earlier survey.

As expected, Burkina Faso, with the highest TFR, had the highest proportion of women who reported that they wanted another child soon (38\%). It also had the lowest proportion of women who wanted to stop childbearing (27\%). In contrast, only 22\% of Kenyan women in 2003 wanted another child soon, and 49\% did not want any more children. Fertility desires in Ghana were intermediate on these two measures (27\% and 35\%, respectively). Fur-
TABLE 2. Percentage distribution of women, by how much of a problem it would be if they became pregnant in the next few weeks, according to fertility intention, contraceptive use and country, 2003

\begin{tabular}{lll|ll|ll|} 
Measure & \multicolumn{2}{l}{ Burkina Faso } & \multicolumn{2}{l}{ Ghana } & \multicolumn{2}{l}{ Kenya } \\
\cline { 2 - 7 } & Nonusers & Users & Nonusers & Users & Nonusers & Users \\
\hline Delay & $(\mathrm{N}=861)$ & $(\mathrm{N}=446)$ & $(\mathrm{N}=372)$ & $(\mathrm{N}=322)$ & $(\mathrm{N}=297)$ & $(\mathrm{N}=421)$ \\
No problem & 16.1 & 23.4 & 16.4 & 17.9 & 37.3 & 43.5 \\
Small problem & 15.9 & 12.2 & 9.2 & 7.9 & 21.1 & 17.6 \\
Big problem & 68.0 & 64.5 & 74.4 & 74.2 & 41.6 & 38.9 \\
& & & & & & \\
Limit & $(\mathrm{N}=845)$ & $(\mathrm{N}=287)$ & $(\mathrm{N}=426)$ & $(\mathrm{N}=289)$ & $(\mathrm{N}=461)$ & $(\mathrm{N}=875)$ \\
No problem & 11.2 & 11.4 & 12.3 & 9.7 & 23.0 & 21.8 \\
Small problem & 7.6 & 7.1 & 7.4 & 5.0 & 8.8 & 12.8 \\
Big problem & 81.2 & 81.5 & 80.2 & 85.3 & 68.2 & 65.4 \\
Total & 100.0 & 100.0 & 100.0 & 100.0 & 100.0 & 100.0
\end{tabular}

thermore, a higher proportion of Ghanaian women wanted to delay childbearing in 2003 than in 1998 (32\% vs. $25 \%$ ), a trend consistent with the slightly higher contraceptive use and higher unmet need in 2003. A similar pattern was found in Burkina Faso, where higher proportions of women wanted to delay or limit childbearing in the later survey. In Kenya, there was little change in fertility desires over the five-year period.

In the 2003 survey, when women who wanted to delay or limit childbearing were asked how much of a problem it would be if they got pregnant in the next few weeks, about three-quarters of those in Burkina Faso and Ghana said it would be a big problem. Conversely, about a quarter said it would be no problem or a small problem. In Kenya, 57\% of women reported that it would be a big problem and 43\% said no problem or a small problem.

In 1998, when women were asked how happy they would be if they got pregnant in the next few weeks, the overwhelming majority of Ghanaian women-82\%-reported that they would be unhappy; the remaining 18\% said they would be happy or that it would not matter. Responses to these related questions from the two surveys show there is little difference in the two measures, suggesting that they capture similar fertility motivations. In Burkina Faso, $81 \%$ of women said they would be unhappy if they became pregnant soon. Among Kenyan women, 63\% said they would be unhappy. In these two countries, only women who wanted to delay childbearing were asked this question in 1998, making com-

\begin{tabular}{|c|c|c|c|c|c|c|}
\hline \multirow[t]{2}{*}{ Reason } & \multicolumn{2}{|c|}{ Burkina Faso } & \multicolumn{2}{|l|}{ Ghana } & \multicolumn{2}{|l|}{ Kenya } \\
\hline & $\begin{array}{l}\text { Delay } \\
(\mathrm{N}=585)\end{array}$ & $\begin{array}{l}\text { Limit } \\
(N=686)\end{array}$ & $\begin{array}{l}\text { Delay } \\
(\mathrm{N}=276)\end{array}$ & $\begin{array}{l}\text { Limit } \\
(\mathrm{N}=342)\end{array}$ & $\begin{array}{l}\text { Delay } \\
(\mathrm{N}=123)\end{array}$ & $\begin{array}{l}\text { Limit } \\
(\mathrm{N}=311)\end{array}$ \\
\hline Side effects or health concerns & 8.7 & 11.8 & 33.0 & 41.8 & 35.2 & 40.2 \\
\hline Infrequent intercourse & 25.5 & 26.8 & 20.3 & 17.4 & 14.6 & 14.7 \\
\hline Husband or partner opposed & 18.7 & 7.1 & 17.1 & 7.7 & 19.6 & 13.2 \\
\hline Lack knowledge of source & 21.1 & 14.8 & 22.0 & 6.6 & 9.9 & 9.4 \\
\hline Cost & 12.1 & 14.1 & 23.8 & 14.2 & 8.0 & 10.8 \\
\hline Menopausal or subfecund & 4.4 & 15.0 & 13.4 & 13.8 & 6.3 & 23.5 \\
\hline
\end{tabular}

Note: Multiple responses were possible. 
TABLE 4. Percentage distribution of women, by how they would feel if they became pregnant in the next few weeks, according to fertility intention, contraceptive use and country, 1998

\begin{tabular}{|c|c|c|c|c|c|c|}
\hline \multirow[t]{2}{*}{ Measure } & \multicolumn{2}{|c|}{ Burkina Faso } & \multicolumn{2}{|l|}{ Ghana } & \multicolumn{2}{|l|}{ Kenya } \\
\hline & Nonusers & Users & Nonusers & Users & Nonusers & Users \\
\hline Delay & $(\mathrm{N}=266)$ & $(\mathrm{N}=150)$ & $(\mathrm{N}=242)$ & $(\mathrm{N}=213)$ & $(\mathrm{N}=261)$ & $(\mathrm{N}=380)$ \\
\hline Happy & 13.4 & 8.4 & 10.4 & 4.3 & 22.1 & 13.6 \\
\hline Would not matter & 7.4 & 7.7 & 14.4 & 20.4 & 17.6 & 21.8 \\
\hline Unhappy & 79.2 & 84.0 & 75.2 & 75.3 & 60.4 & 64.6 \\
\hline Limit & & & $(\mathrm{N}=431)$ & $(\mathrm{N}=239)$ & & \\
\hline Happy & na & na & 3.0 & 0.0 & na & na \\
\hline Would not matter & na & na & 13.9 & 9.2 & na & na \\
\hline Unhappy & na & na & 83.1 & 90.8 & na & na \\
\hline Total & 100.0 & 100.0 & 100.0 & 100.0 & 100.0 & 100.0 \\
\hline
\end{tabular}

Note: na=not available.

parison between the two surveys difficult.

In 2003, among women in Burkina Faso who wanted to delay childbearing and did not practice contraception, $68 \%$ said it would be a big problem if they became pregnant in the next few weeks, and 32\% said it would be no problem or a small problem (Table 2, page 187). Among those who reported that they wanted to delay childbearing and were practicing contraception, $65 \%$ said it would be a big problem if they became pregnant soon. Among both contraceptive users and nonusers in Burkina Faso who wanted to limit childbearing, more than $80 \%$ said it would be a big problem if they became pregnant in the next few weeks. The 2003 findings for Ghana are surprisingly similar to those for Burkina Faso: About eight in 10 Ghanaian women who wanted to delay or limit childbearing said it would be a big problem if they got pregnant.

The data from Kenya tell a different story. In 2003, six in 10 women who wanted to delay childbearing-both those who practiced contraception and those who did not-said that it would be no problem or a small problem if they became pregnant in the next few weeks. Thus a majority of these women were ambivalent about future childbearing. Among Kenyan women who wanted to limit childbearing, one-third said it would be no problem or a small problem if they got pregnant; this level of ambivalence was higher than that in the other two countries.

Among women in Burkina Faso who said it would be a big problem if they became pregnant, wanted to delay childbearing and did not use contraceptives, the most common reasons for nonuse were infrequent intercourse, not know-

TABLE 5. Percentage distribution of women with an unmet need for means of delaying or limiting childbearing, by how much of a problem it would be if they became pregnant in the next few weeks, according to country, 2003

\begin{tabular}{|lll|ll|ll} 
Measure & \multicolumn{3}{l|l}{ Burkina Faso } & Ghana & \multicolumn{2}{l}{ Kenya } \\
\cline { 2 - 7 } & $\begin{array}{l}\text { Delay } \\
(\mathrm{N}=856)\end{array}$ & $\begin{array}{l}\text { Limit } \\
(\mathrm{N}=441)\end{array}$ & $\begin{array}{l}\text { Delay } \\
(\mathrm{N}=365)\end{array}$ & $\begin{array}{l}\text { Limit } \\
(\mathrm{N}=281)\end{array}$ & $\begin{array}{l}\text { Delay } \\
(\mathrm{N}=292)\end{array}$ & $\begin{array}{l}\text { Limit } \\
(\mathrm{N}=273)\end{array}$ \\
\hline No problem & 14.0 & 9.6 & 15.4 & 10.3 & 34.5 & 19.8 \\
Small problem & 16.9 & 7.8 & 10.5 & 5.4 & 21.6 & 10.3 \\
Big problem & 69.2 & 82.6 & 74.1 & 84.3 & 43.9 & 69.9 \\
Total & 100.0 & 100.0 & 100.0 & 100.0 & 100.0 & 100.0
\end{tabular}

ing a source, husband or partner opposition, and cost (Table 3 , page 187). Among women who reported infrequent intercourse, $57 \%$ said their last sexual encounter had occurred six or more months earlier (not shown). The major reasons for nonuse among women who wanted to delay childbearing and said it would be no problem or a small problem included not knowing a source, infrequent intercourse, and husband or partner opposition. For those who wanted to limit childbearing and said it would be a big problem, the most common reasons for nonuse were infrequent intercourse, being menopausal or subfecund, not knowing a source and cost. Only a quarter of those citing infrequent intercourse had had their last sexual encounter at least six months previously. Women who wanted to limit childbearing and said pregnancy would be no problem or a small problem cited similar reasons.

Among Ghanaian and Kenyan women who wanted to delay or limit births and said it would be a big problem if they became pregnant soon, more than a third of nonusers reported that side effects or health concerns kept them from practicing contraception. Other common reasons given by women in Ghana who wanted to delay childbearing were cost, not knowing a source and infrequent intercourse. Kenyan women who wanted to delay births also cited husband or partner opposition, while those who wanted to limit births cited being menopausal or subfecund.

Among women in Burkina Faso who wanted to delay childbearing in 1998, 21\% of contraceptive nonusers and $16 \%$ of users said becoming pregnant soon would make them happy or would not matter (Table 4). In 1998, as in 2003, about a quarter of Ghanaian women who wanted to delay childbearing were ambivalent, answering that they would be happy or that it would not matter if they soon became pregnant. The proportions who wanted to limit childbearing in 1998 and said they would be unhappy if they got pregnant (83\% of nonusers and $91 \%$ of users) were similar to the proportions in 2003 who said a pregnancy would be a big problem. This suggests that these two measures are capturing similar fertility motivations in the two surveys.

More than a third of Kenyan women who reported in 1998 that they wanted to delay childbearing-whether or not they practiced contraception-said they would be happy or that it would not matter if they became pregnant in the next few weeks. Notably, when women from Burkina Faso and Kenya who wanted to get pregnant in the near future were asked this question, the overwhelming majority of those not using contraceptives said they would be happy if they got pregnant (87\% and 92\%, respectively-not shown). This suggests that the measure accurately reflects the degree to which women want to get pregnant in these countries.

In Burkina Faso and Ghana in 2003, 31\% and 26\%, respectively, of women with an unmet need for means of delaying childbearing said becoming pregnant soon would be no problem or a small problem, whereas more than twothirds viewed it as a big problem (Table 5). Among women in these two countries who had an unmet need for means 
of limiting childbearing, only $16 \%$ and $17 \%$, respectively, said it would be no problem or a small problem, while more than $80 \%$ said it would be a big problem.

The unmet need findings for Kenya show a different pattern. Among women with an unmet need for means of delaying childbearing, $56 \%$ said it would be no problem or a small problem if they became pregnant in the next few weeks. Among women with an unmet need for means of limiting childbearing, 30\% said it would be no problem or a small problem if they got pregnant soon. Hence, the proportions of Kenyan women with an unmet need who were ambivalent were nearly twice as large as those in Burkina Faso and Ghana.

\section{DISCUSSION}

These findings from three Sub-Saharan African countries demonstrate the importance of considering the strength of women's fertility motivations when determining who has a need for family planning services. As in studies from the United States, at least a quarter of women who want to delay or limit childbearing appear to be ambivalent about future childbearing. Moreover, although the level of contraceptive use was highest in Kenya, women in this country also reported the highest levels of ambivalence about childbearing. Yet in all three countries, large proportions of both users and nonusers of family planning gave ambivalent responses. Women who are ambivalent may be less likely than other women to initiate contraceptive use or more likely to discontinue use if they experience side effects or opposition from their husband or partner. Ambivalent users may also be more likely to use methods inconsistently.

These results suggest that two groups of women should be of particular interest to family planning providers. The first group includes women who want to delay childbearing, are not practicing contraception and say that it would be a big problem if they soon became pregnant. These women need information on short-term methods and where to obtain them, information on side effects to reduce fears and allay health concerns, and outreach programs to change partner and community norms opposing contraceptive use. Qualitative studies would improve our understanding of why these women-who are the most motivated to delay childbearing-have such low rates of contraceptive use.

The second group includes women who want to limit childbearing, are not practicing contraception and say it would be a big problem if they became pregnant soon. Notably, many women in this group perceive themselves to be infecund or subfecund. Yet if they are indeed fecund, they may experience an unintended pregnancy. Mass media programs that encourage women to use family planning when they no longer want children may help some of these women recognize their need for long-term family planning and help them gain access to such services.

It is critical to encourage consistent use for women who have recently adopted a contraceptive method. However, some of these women may be ambivalent and at risk of dis- continuing use, and our data indicate that at least a quarter of those who use contraceptives to delay childbearing might report unexpected pregnancies as being intended. If the goal is to reduce unintended pregnancies, these ambivalent users may not be the best group to target.

Kenya's fertility transition has not continued: Fertility rates have risen and contraceptive use is no longer increasing. ${ }^{15}$ Furthermore, the country's overall contraceptive discontinuation rate over 12 months rose from 33\% to 38\% between 1998 and 2003, ${ }^{16}$ which may lead to an increase in fertility while levels of contraceptive use remain unchanged. Although this study cannot explain these trends, it does offer some insight. In particular, we find that Kenyan women overall are more ambivalent about future childbearing than women in Ghana and Burkina Faso, and it appears that their ambivalence has risen over this five-year period. Why is the fertility situation in Kenya different?

First, Kenya's fertility transition is further advanced than those in Ghana and Burkina Faso. It is possible that levels of ambivalence rise in the later stages of a country's fertility transition. As smaller family sizes become the norm, larger proportions of women who report a desire to delay or limit childbearing may follow the trend but hold these desires somewhat weakly. For example, although having a third or fourth child may not be considered ideal, it may not be unattractive to these women either. Second, because of the devastating consequences of the AIDS epidemic in Kenya since the 1990s, it is possible that the fear of losing a family member or a child has led to a growing demand for more children. ${ }^{17}$

A third explanation is that there was decreasing emphasis on information, education and communication programs in Kenya during the study period, ${ }^{18}$ and this decline in outreach efforts may have led to a drop in parents' desire for smaller families. The fourth possibility is methodological: The 1998 and 2003 questions measuring how happy a woman would be and how much of a problem it would be if she were to get pregnant soon may not be capturing similar fertility motivations in Kenya. Qualitative research is needed to help us better understand whether ambivalence has changed over time and how it has affected fertility rates and contraceptive use. This analysis found changes that suggest a decline in use of family planning services and a rise in fertility, but they do not tell us why these changes are being observed.

\section{Limitations}

This study has a number of limitations. First, the data used to examine the strength of fertility motivations and ambivalence were cross-sectional and derived from only a few measures. It was not possible to determine whether inconsistencies between fertility desires and feelings about getting pregnant in the near future reflected true ambivalence or simply pronatalist views. Moreover, we could not assess whether women who became pregnant as a result of contraceptive failure subsequently considered the pregnancy to be intended or unintended. Second, this study in-
At leasta

quarter of

women who

want to delay or

limit childbear-

ing appear to be

ambivalent

about future

childbearing. 
cludes only women's fertility desires and perspectives on childbearing. The inclusion of their partners' perspectives would improve our understanding of why some women appear ambivalent, especially given that partner opposition was often cited as a reason for not using contraceptives. Furthermore, studies of couples have demonstrated that male partners exert considerable influence over women's use of family planning services. ${ }^{19}$

Another limitation is that the strength of fertility motivations was measured by different questions on the two surveys, which raises the possibility that the observed differences were a consequence of translation and interpretation issues. However, the consistency in fertility motivation between the two time periods for Ghana suggests that these measures may be capturing similar attitudes. In Kenya, it is not possible to tell whether differences over time reflect a true variation in levels of ambivalence or simply a variation attributable to the questions themselves. Cultural and language differences among the countries may further reduce the overall comparability of responses.

\section{Conclusions}

This study shows why family planning programs need to employ more than just the concept of unmet need to target women (and men) in Sub-Saharan Africa. At least a quarter of women with an unmet need appear to be ambivalent about their childbearing and might not use family planning even if it were accessible, affordable and provided in a highquality setting. And even if these women did adopt family planning, they might be at high risk of contraceptive failure, discontinuation or inconsistent use.

This study has revealed three main program strategies. First, programs should target women who do not practice contraception but are highly motivated to avoid pregnancy. These women could be identified through one-on-one discussions when they visit health facilities for their own health needs or those of their children. A systematic screening algorithm meant to integrate reproductive health services into other clinic-based services may be an ideal method for identifying such women. ${ }^{20}$ Furthermore, outreach workers could be sent to locations where women congregate, such as markets, work-based settings and taxi stands. These workers could use a brief screening tool to help identify the most motivated women and direct them to family planning services when appropriate.

A second strategy involves training service providers to offer contraceptive users information on how to use methods, what to do if they experience side effects and how to choose an alternative method, all of which would encourage more effective use among women who have strong motivations to avoid pregnancy. This approach could result in better short- and long-term continuation rates, as well as more consistent use. Finally, while much emphasis has been placed on community outreach to increase access to family planning methods, it is also important to strengthen community-based strategies that affect fertility demand so that women who are being offered services develop strong motivations and desires to adopt and continue to use contraceptive methods. Recognizing women's (and men's) ambivalence toward future pregnancies may be a critical help in developing appropriate strategies for both identifying and retaining contraceptive users with the overall goal of reducing unintended pregnancies.

\section{REFERENCES}

1. Bongaarts J, Trends in unwanted childbearing in the developing world, Studies in Family Planning, 1997, 28(4):267-277.

2. Jain A, Should eliminating unmet need for contraception continue to be a program priority? International Family Planning Perspectives, 1999, 25(Suppl.):S39-S42 \& S49; and Blanc AK, Curtis SL and Croft TN, Monitoring contraceptive continuation: links to fertility outcomes and quality of care, Studies in Family Planning, 2002, 33(2):127-140.

3. Blanc AK, Curtis SL and Croft TN, 2002, op. cit. (see reference 2).

4. Jain A, 1999, op. cit. (see reference 2); and Blanc AK, Curtis SL and Croft TN, 2002, op. cit. (see reference 2).

5. Casterline JB, El-Zanaty F and El-Zeini LO, Unmet need and unintended fertility: longitudinal evidence from Upper Egypt, International Family Planning Perspectives, 2003, 29(4):158-166.

6. Santelli J et al., The measurement and meaning of unintended pregnancy, Perspectives on Sexual and Reproductive Health, 2003, 35(2): 94-101; Luker KC, A reminder that human behavior frequently refuses to conform to models created by researchers, Family Planning Perspectives, 1999, 31(5):248-249; and Bachrach CA and Newcomer $\mathrm{S}$, Intended pregnancies and unintended pregnancies: distinct categories or opposite ends of a continuum? Family Planning Perspectives, 1999, 31(5):251-252.

7. Trussell J, Vaughan B and Stanford J, Are all contraceptive failures unintended pregnancies? evidence from the 1995 National Survey of Family Growth, Family Planning Perspectives, 1999, 31(5):246-247 \& 260.

8. Westoff CF and Bankole A, The time dynamics of unmet need: an example from Morocco, International Family Planning Perspectives, 1998, 24(1):12-14 \& 24.

9. Zabin LS, Ambivalent feelings about parenthood may lead to inconsistent contraceptive use-and pregnancy, Family Planning Perspectives, 1999, 31(5):250-251.

10. The Acquire Project, Moving Family Planning Programs Forward: Learning from Success in Zambia, Malawi, and Ghana, New York: The Acquire Project/Engender Health, 2005.

11. Westoff CF, Unmet Need at the End of the Century, DHS Comparative Reports, Calverton, MD, USA: ORC Macro, 2001, No. 1.

12. Bongaarts J, The causes of stalling fertility transitions, paper presented at the International Union for the Scientific Study of Population XXV International Population Conference, Tours, France, July 18-23, 2005

13. Ross J, Abel E and Abel K, Plateaus during the rise of contraceptive prevalence, International Family Planning Perspectives, 2004, 30(1):39-44.

14. Institut National de la Statistique et de la Démographie (INSD) and Macro International, Burkina Faso Enquête Démographique et de Santé, 1998-1999, Calverton, MD, USA: Macro International, 2000; INSD and ORC Macro, Burkina Faso Enquête Démographique et de Santé, 2003, Calverton, MD, USA: ORC Macro, 2004; Ghana Statistical Service (GSS) and Macro International, Ghana Demographic and Health Survey, 1998, Calverton, MD, USA: Macro International, 1999; GSS, Noguchi Memorial Institute for Medical Research and ORC Macro, Ghana Demographic and Health Survey, 2003, Calverton, MD, USA: ORC Macro, 2004; National Council for Population and Development, Central Bureau of Statistics (CBS) and Macro International, Kenya Demographic and Health Survey, 1998, Calverton, MD, USA: Macro International, 1999; and CBS, Ministry of Health and ORC Macro, Kenya Demographic and Health Survey, 2003, Calverton, MD, USA: ORC Macro, 2004.

15. Bongaarts J, 2005, op. cit. (see reference 12); Westoff CF and Cross 
$\mathrm{AR}$, The stall in the fertility transition in Kenya, paper presented at the International Union for the Scientific Study of Population XXV International Population Conference, Tours, France, July 18-23, 2005; and Koome P, Nturibi D and Kichamu G, The effect of declining family planning IEC efforts on contraceptive behaviour, working paper, Nairobi, Kenya: National Coordinating Agency for Population and Development, 2005.

16. CBS, Ministry of Health and ORC Macro, 2004, op. cit. (see reference 14).

17. Westoff CF and Cross AR, 2005, op. cit. (see reference 15).

18. Koome P, Nturibi D and Kichamu G, 2005, op. cit. (see reference 15).

19. Becker S, Measuring unmet need: wives, husbands or couples? International Family Planning Perspectives, 1999, 25(4):172-180.

20. Foreit J, Systematic Screening: A Strategy for Determining and Meeting Clients' Reproductive Health Needs, FRONTIERS Program Brief, Washington, DC: Population Council, 2006, No. 6.

\section{RESUMEN}

Contexto: El uso de la necesidad insatisfecha en anticoncepción para identificar a las posibles clientas puede ofrecer una información errónea sobre la verdadera necesidad de una población, dado que un gran porcentaje de mujeres tiene deseos ambivalentes en materia de fecundidad.

Métodos: Se utilizaron datos de las encuestas realizadas en 1998 y 2003 en Burkina Faso, Ghana y Kenya, para examinar los deseos de fecundidad y las motivaciones de las mujeres que deseaban postergar o limitar su fecundidad. Se formuló una pregunta acerca de cuán problemático sería para una mujer si quedara embarazada durante las próximas semanas; con esta pregunta se midió la solidez de sus motivaciones en materia de fecundidad. Resultados: En Burkina Faso y Ghana, alrededor de la cuarta parte de las mujeres que indicaron que deseaban postergar o limitar su maternidad, también indicaron que no sería un problema o que sería un problema pequeño si hubieran quedado embarazadas enseguida. Este tipo de respuesta fue igualmente común entre las usuarias de anticonceptivos que entre las no usuarias. En Kenya, más de cuatro de cada 10 mujeres dieron respuestas ambivalentes. Entre las mujeres que presentaban una necesidad insatisfecha de postergar o limitar la fecundidad, el 16-31\% de las de Burkina Faso y Ghana, y el 30-56\% de las de Kenya, indicaron que si quedaran embarazadas durante las próximas semanas no sería un problema o sería un problema pequeño.

Conclusiones: Tiene importancia crítica tomar en cuenta la solidez de las motivaciones sobre la fecundidad cuando se de- termina cuáles mujeres tienen necesidad de servicios de planificación familiar. Se logrará el mayor impacto en la reducción de los embarazos no planeados en el África subsahariana al concentrar la atención en las mujeres que son las más motivadas para evitar la maternidad.

\section{RÉSUMÉ}

Contexte: L'emploi du besoin non satisfait de planification familiale dans le but d'identifier les clientes prospectives ne représente pas nécessairement la mesure réelle des besoins d'une population, étant donné la proportion importante de fermmes dont les désirs de fécondité sont ambivalents.

Méthodes: Les données d'enquête recueillies en 1998 et 2003 au Burkina Faso, au Ghana et au Kenya servent à l'examen des désirs et motivations de fécondité des femmes ayant déclaré vouloir différer ou limiter leur procréation. La question de savoir si la découverte d'une grossesse durant les quelques semaines à venir représenterait un grave problème pour la femme permet de mesurer la fermeté de ses motivations de fécondité.

Résultats: Au Burkina Faso et au Ghana, environ un quart des femmes qui avaient déclaré vouloir différer ou limiter leur procréation ont également affirmé qu’une prochaine grossesse éventuelle ne serait pas ou guère problématique. La tendance s'est révélée égale parmi les utilisatrices ou non de la contraception. Au Kenya, plus de quatre femmes sur 10 ont donné ce type de réponses ambivalentes. Parmi les femmes présentant un besoin non satisfait de moyens de différer ou de limiter leur procréation, 16\% à 31\% des Burkinabé et des Ghanéennes et 30\% à 56\% des Kenyanes ont répondu de même à cette question.

Conclusions: Il est essentiel de considérer la fermeté des motivations de fécondité lors de l'identification des femmes ayant un besoin de planification familiale. Le ciblage des femmes les plus motivées à éviter la maternité produira vraisemblablement le plus d'impact sur la réduction des grossesses non planifiées en Afrique subsaharienne.

\section{Acknowledgments}

This research was supported by the U.S. Agency for International Development (USAID) under cooperative agreement GPO-A-0003-00003-00 with the MEASURE Evaluation Project. The views expressed here are those of the author and not necessarily those of USAID. The author thanks Alan Johnston, Janine Barden-O'Fallon and Siân Curtis for their helpful insights.

Author contact:speizer@email.unc.edu 